\title{
Development of Technological Process of Matrix Conversion of Natural and Associated Petroleum Gases into Syngas with Low Content of Nitrogen
}

\author{
V.S. Arutyunov, A.V. Nikitin, V.I. Savchenko, I.V. Sedov, \\ O.V. Shapovalova and V.M. Shmelev
}

\begin{abstract}
There is an acute need in more wide use of huge world resources of natural gas as a petrochemical raw material. But solving of this global task is hardly possible without developing of more effective methods for conversion of natural gas into the most important gas-chemical intermediate-syngas. This paper describes recent results on a principally new type of reformers based on the non-catalytic conversion of hydrocarbons into syngas in volumetric (3D) matrix burners. The use of enriched air and oxygen results in production of syngas with low content of nitrogen for petrochemical applications, including production of methanol, syncrude oil, and others. The effective recuperation of heat of produced syngas inside the matrix cavity permits to operate at optimal values of oxygen excess coefficient $\alpha=0.32-0.36$, thus making it possible to obtain in such simple non-catalytic process very high yield of nitrogen-free syngas with concentration of $\mathrm{H}_{2}$ more than $50 \%$ and that of CO more than $30 \%$.
\end{abstract}

\footnotetext{
V.S. Arutyunov $(\square) \cdot$ A.V. Nikitin · O.V. Shapovalova · V.M. Shmelev

Semenov Institute of Chemical Physics, Russian Academy of Sciences, Moscow, Russia e-mail: v_arutyunov@mail.ru
}

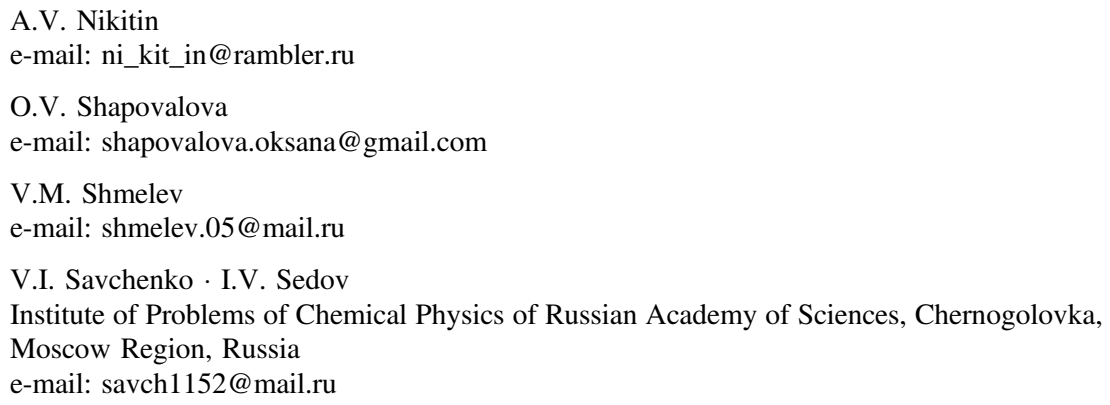


Keywords Natural gas - Associated petroleum gas - Syngas - Partial oxidation Combustion limits · Volumetric matrix burners

\section{Introduction}

Huge world resources of natural gas, about two orders of magnitude above that of oil [1], is the main source of energy and hydrocarbons for the nearest future. Because modern civilization strongly depends on the wide use of liquid hydrocarbon fuels and different petrochemicals, it will be necessary to replace many of petrochemical processes by gas chemical technologies to use the abundant gas resources as petrochemical raw material. But modern gas chemistry technologies are too complex and costly and cannot compete today with petrochemistry in the production of liquid motor fuels and other important chemicals [2]. The main problem is that practically all multi-tonnage gas chemical processes need preliminary conversion of natural gas into syngas (the mixture of $\mathrm{H}_{2}$ and $\mathrm{CO}$ ), which can be more easily converted into liquid hydrocarbons and chemicals. This very complex, energy, and capital-intensive stage consumes up to $70 \%$ of all expenditures for obtaining final products [3]. Therefore, global gas chemistry urgently needs more simple and effective technologies for natural gas conversion into syngas. Nowadays, the absence of such technologies seriously restricts the more wide use of natural gas as a petrochemical raw material. In spite that a number of alternative technologies for natural gas conversion to syngas were announced in literature during last decades [3], up to now no one of them has shown its practical consistency. This paper describes recent results obtained by development of principally new approach to solve this very important global task, which is based on the use of volumetric (3D) matrix burners [4-8].

\section{Basic Principles of Matrix Conversion}

Matrix conversion of hydrocarbon gases into syngas is based on so-called "flameless" combustion, when flame front is stabilized on the surface of a solid porous or perforated planar matrix. Such type of combustion is widely used for many technological applications, first of all as a source of IR radiation $[9,10]$. In this case, the flame front is stabilized at some distance above the surface, with its temperature being low enough, $\sim 1000-1200{ }^{\circ} \mathrm{C}$, due to intense convective and radiation heat transfer from the flame front to the surface. The surface heated in this manner intensely radiates in the IR region and can be used as an effective source of IR radiation for many practical applications. However, intense convective and radiation loss from the flame front significantly narrow the combustion limits.

To widen the combustion limits and ensure the combustion of lean gas mixtures with low NOx emissions, it was suggested to use 3D permeable matrixes with a 
closed inner cavity [11-14]. It was demonstrated that, in such matrix burners, the stable combustion of very lean mixtures at an oxygen excess coefficient of $\alpha=\left[\mathrm{O}_{2}\right] / 2\left[\mathrm{CH}_{4}\right]>2$ can occur at a specific combustion power of up to $30-40 \mathrm{~W} / \mathrm{cm}^{2}$. These conditions provide very low concentrations of nitrogen oxides and carbon monoxide. Theoretically, estimated temperatures of the flame front and that at the entrance and working surfaces of such $3 \mathrm{D}$ matrixes were found to be in good agreement with the available experimental data [11, 12].

The same organization of the combustion process makes it possible to widen the combustion limits for rich mixtures as well, thus providing necessary conditions for an effective conversion of hydrocarbons into syngas [4-8]. The principal scheme of a syngas reformer based on a 3D permeable matrix is shown in Fig. 1. After passing the mixer, a homogeneous fuel-oxidizer mixture of specified composition is fed through permeable walls of the 3D matrix burner into its inner cavity, where it burns near the surface. Due to a very intense convective and radiant transfer of heat from flame front and combustion products to the matrix walls and then to the incoming fresh gas, the temperature of the gas mixture entering the flame front increases up to $400-600{ }^{\circ} \mathrm{C}$, while that of flame front and combustion products decreases to $1000-1200{ }^{\circ} \mathrm{C}$. Alongside with the absence of radiation losses in the closed cavity of the matrix, it lowers the limit of stable combustion of rich methane-oxidizer mixtures to a value of oxygen excess coefficient $\alpha=0.32-0.36$ and thus enables to attain yields of $\mathrm{H}_{2}$ and $\mathrm{CO}$ very close to the thermodynamically equilibrium values.

Fig. 1 Principal scheme of matrix burner with a deep volumetric (3D) matrix. 1external shell, 2-volume with a fuel-air mixture, 3 gas outlet, 4-side walls and bottom made from perforated ceramic, 5-cap made from perforated ceramic

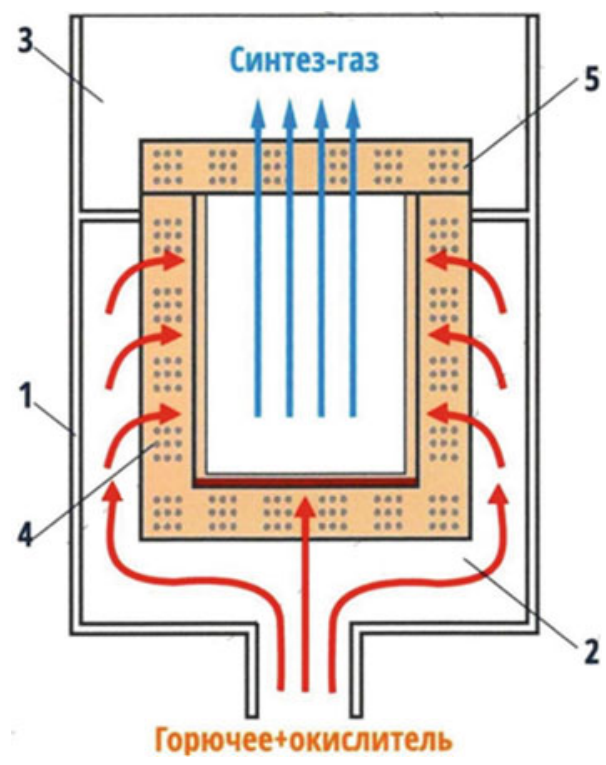




\section{Pilot Installations for Matrix Conversion Testing}

Several series of laboratory scale investigations that were thoroughly described in [4-8] have shown principal features and possibilities of matrix conversion. The purpose of this study was the pilot testing and demonstration of matrix conversion ability to produce nitrogen-free syngas for subsequent use in methanol and FisherTropsch synthesis.

Two pilot installations were used in this study. The first one was designed for testing the process at atmospheric pressure with input gas flows up to $20 \mathrm{~m}^{3} / \mathrm{h}$ (Fig. 2). Two matrix cavities were formed by two pairs of flat square porous plates with dimensions $250 \times 250 \mathrm{~mm}$ made from metallic foam or metallic wool.

The second installation was designed for testing the process at enhanced pressures with input gas flows up to $10 \mathrm{~m}^{3} / \mathrm{h}$ (Fig. 3). It has one matrix cavity formed by the pair of flat porous circular plates with diameter $200 \mathrm{~mm}$. Plates were also made from metallic foam or metallic wool. After several series of testing of different matrixes in both installations, it was concluded that the best choice is metallic wool matrixes with the width of about $8 \mathrm{~mm}$ fabricated by pressing of coiled Nichrome wire with $0.1-0.2 \mathrm{~mm}$ diameter. In both cases, the round stainless steel apertures with a diameter of 100 or $150 \mathrm{~mm}$ were installed before matrix to decrease marginal effects, especially for rectangular matrixes. Behind matrixes thin stainless steel screens were situated to reflect IR radiation of flame front back to the matrix, thus

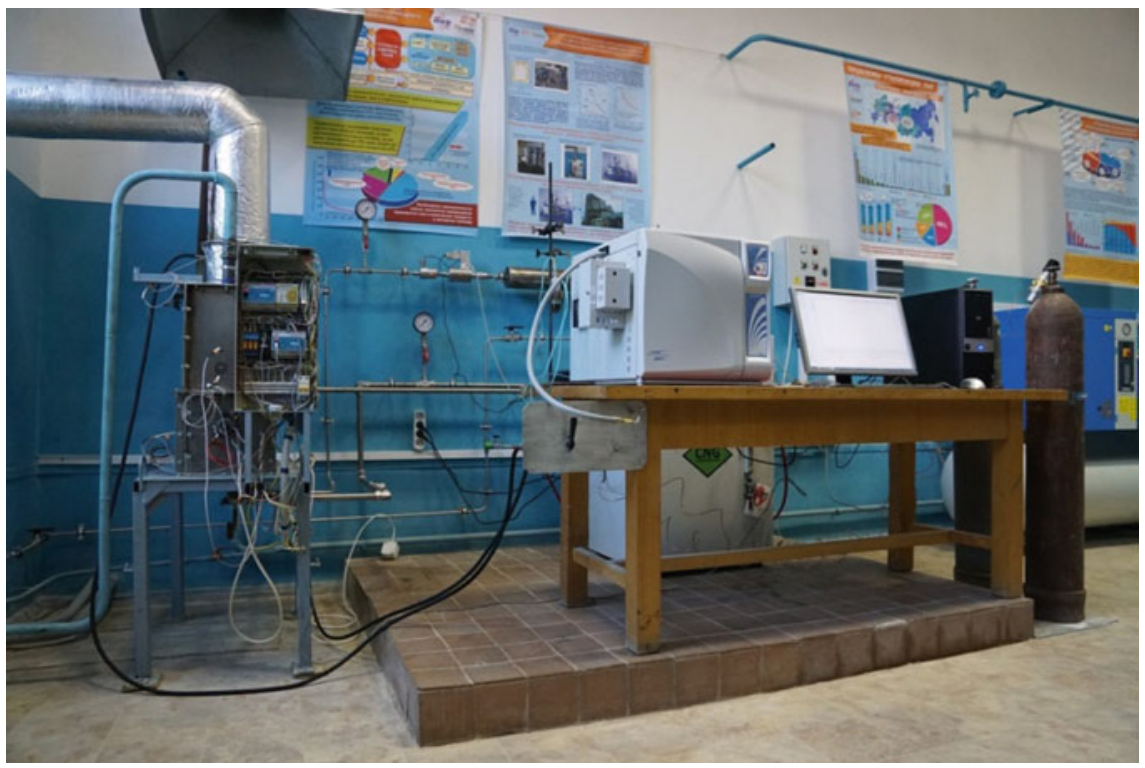

Fig. 2 Pilot installation for matrix conversion of natural gas at atmospheric pressure. Input natural gas capacity up to $20 \mathrm{~m}^{3} / \mathrm{h}$ 


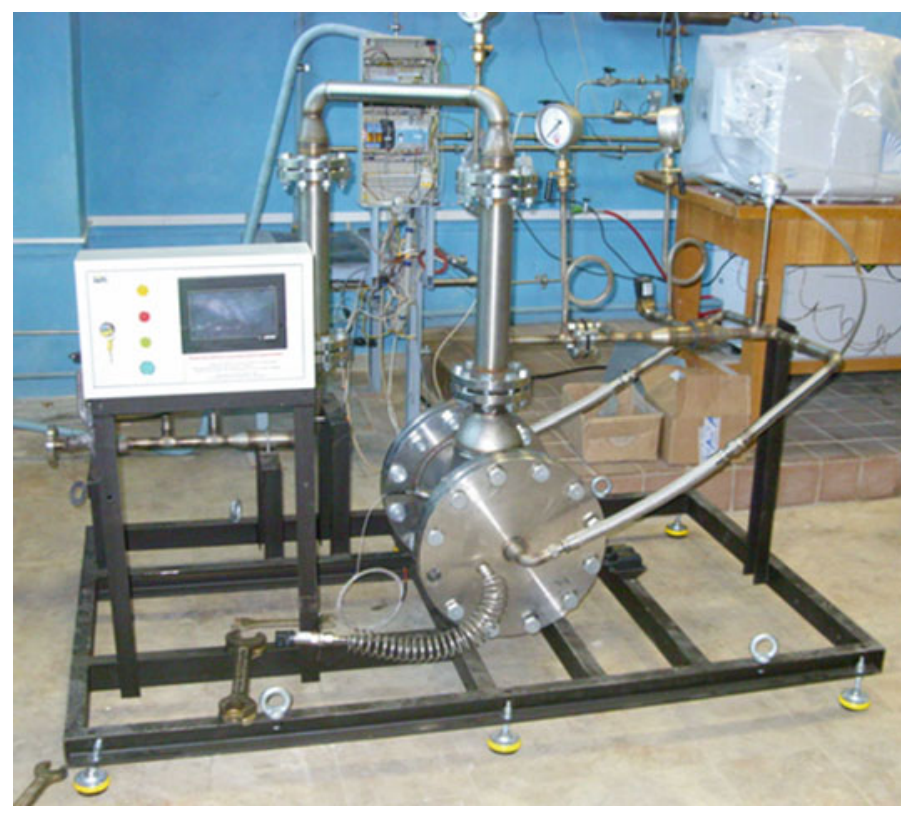

Fig. 3 Pilot installation for matrix conversion of natural gas at enhanced pressures. Input natural gas capacity up to $10 \mathrm{~m}^{3} / \mathrm{h}$

enhancing the recuperation of heat. In all testing, cylinders with natural gas used for fueling city buses and technical grade oxygen were used.

\section{Results and Discussion}

The first series of testing was accomplished at atmospheric pressure with pilot installation shown in Fig. 2 with atmospheric air as an oxidant. It was shown the possibility of stable conversion of natural gas by atmospheric air at values of oxygen excess coefficient $\alpha$ as low as 0.30 and even lower. But the best results were obtained at values of $\alpha=0.34-0.36$. At lower values of oxygen excess coefficient, the conversion of natural gas decreases thus decreasing the yield of syngas. The oxidation by air at optimal values of oxygen excess coefficient results in the production of syngas with concentration of $\mathrm{H}_{2}$ up to $25 \%$, of $\mathrm{CO}$ up to $15 \%$ and $\mathrm{H}_{2} / \mathrm{CO}$ ratio about 1.6. At this, the conversion of both methane and oxygen was above $95 \%$. These figures are very close to thermodynamically equilibrium figures for these conditions. Therefore, matrix conversion by atmospheric air results in relatively easy production of inexpensive syngas which can be used, for example, in simple small-scale technologies for natural or associated petroleum gas conversion into liquid hydrocarbons just in the field conditions $[15,16]$. 
Series of testing under enhanced pressures up to 5 atm with pilot installation presented in Fig. 3 have shown the principal possibility of matrix converters operation at enhanced pressure. Nevertheless, significant difficulties induced by very intensive heat release on matrix surface at enhanced pressures that lead to matrix overheating make it desirable to look for some alternative solutions concerning the design and operation of matrix converter at enhanced pressure.

The results of several series of testing with both pilot installations presented in Figs. 2 and 3 with enriched air and technical oxygen are presented in Table 1 and in Figs. 4, 5, and 6.

As it can be seen from Table 1 and Fig. 4, enriching of oxidizer by oxygen leads to a steadily increasing of hydrogen and carbon monoxide concentrations in syngas. This increase is directly proportional to oxygen concentration and can be simply the consequence of decreasing of nitrogen concentration. The concentrations of principal products increase up to values about $54 \%$ for $\mathrm{H}_{2}$ and about $31 \%$ for $\mathrm{CO}$. The concentration of $\mathrm{CO}_{2}$ at that changes insignificantly, from $3.6 \%$ at oxidation by air to slightly above $5 \%$ at oxidation by oxygen. Taking into account the decreasing of nitrogen concentration, it means that the carbon selectivity of syngas production changes insignificantly with the increase of oxygen content in oxidizer in spite of the increase of the specific heat release with the decrease of nitrogen content in products. The conversion of oxygen is practically always complete, and that of methane is up to $88 \%$ at oxidation by oxygen, while practically complete at oxidation by air. Some structural improvements of converter construction are now

Table 1 Experimental results of natural gas conversion to syngas with air, enriched air and technical oxygen in pilot installations presented in Figs. 2 and 3 at values of oxygen excess coefficient $\alpha=0.34-0.36$

\begin{tabular}{l|l|l|l|l|l|l|l|l|l}
\hline \multirow{2}{*}{$\begin{array}{l}\mathrm{O}_{2}, \\
\%\end{array}$} & \multicolumn{3}{|l}{ Concentration of products, $\%$} & \multicolumn{2}{l}{$\mathrm{H}_{2} / \mathrm{CO}$} & \multicolumn{2}{l}{ Conversion, \% } \\
\cline { 2 - 8 } & $\mathrm{H}_{2}$ & $\mathrm{CO}_{2}$ & $\mathrm{O}_{2}$ & $\mathrm{~N}_{2}$ & $\mathrm{CH}_{4}$ & $\mathrm{CO}$ & & $\mathrm{CH}_{4}$ & $\mathrm{O}_{2}$ \\
\hline 21.0 & 22.2 & 3.6 & 0.6 & 47.1 & 0.5 & 13.8 & 1.61 & 97.0 & 95.2 \\
\hline 21.0 & 23.0 & 3.6 & 0.6 & 48.0 & 0.6 & 14.4 & 1.60 & 96.6 & 95.3 \\
\hline 21.0 & 23.7 & 3.7 & 0.6 & 45.1 & 1.0 & 14.2 & 1.67 & 94.3 & 95.0 \\
\hline 24.4 & 25.0 & 3.6 & 0.8 & 45.9 & 0.6 & 15.6 & 1.61 & 97.1 & 94.9 \\
\hline 25.4 & 19.9 & 3.9 & 1.6 & 49.3 & 1.9 & 12.8 & 1.55 & 91.4 & 90.5 \\
\hline 25.4 & 19.6 & 4.2 & 1.3 & 49.8 & 1.9 & 12.6 & 1.56 & 91.9 & 92.3 \\
\hline 47.3 & 27.8 & 4.7 & 0.6 & 29.2 & 9.9 & 19.2 & 1.45 & 74.6 & 97.8 \\
\hline 47.3 & 33.0 & 3.8 & 0.2 & 31.1 & 6.2 & 20.9 & 1.58 & 83.9 & 99.2 \\
\hline 60.5 & 32.1 & 3.7 & 0.4 & 20.4 & 8.4 & 23.1 & 1.39 & 81.5 & 98.8 \\
\hline 100 & 51.8 & 5.5 & 0.2 & 0.5 & 9.2 & 30.3 & 1.71 & 84.1 & 99.6 \\
\hline 100 & 53.4 & 5.3 & 0.0 & 0.4 & 7.9 & 30.6 & 1.74 & 86.2 & 100.0 \\
\hline 100 & 54.0 & 5.2 & 0.0 & 0.4 & 7.2 & 31.2 & 1.73 & 87.0 & 100.0 \\
\hline 100 & 51.9 & 5.5 & 0.0 & 0.4 & 9.3 & 30.8 & 1.68 & 84.1 & 99.9 \\
\hline 100 & 54.5 & 5.1 & 0.0 & 0.3 & 6.4 & 31.4 & 1.74 & 88.4 & 100.0 \\
\hline 100 & 53.8 & 5.1 & 0.0 & 0.3 & 7.2 & 31.7 & 1.70 & 86.7 & 100.0 \\
\hline 100 & 53.0 & 5.2 & 0.0 & 0.4 & 8.0 & 30.9 & 1.72 & 85.9 & 100.0 \\
\hline
\end{tabular}


Fig. 4 Dependence of the concentration of principal syngas components on oxygen content in oxidizer at oxygen excess coefficient $\alpha=0.34-0.36$

Fig. 5 Dependence of the concentration of principal syngas components on oxygen excess coefficient $\alpha$ at methane conversion by oxygen

\section{Concentration, \%}

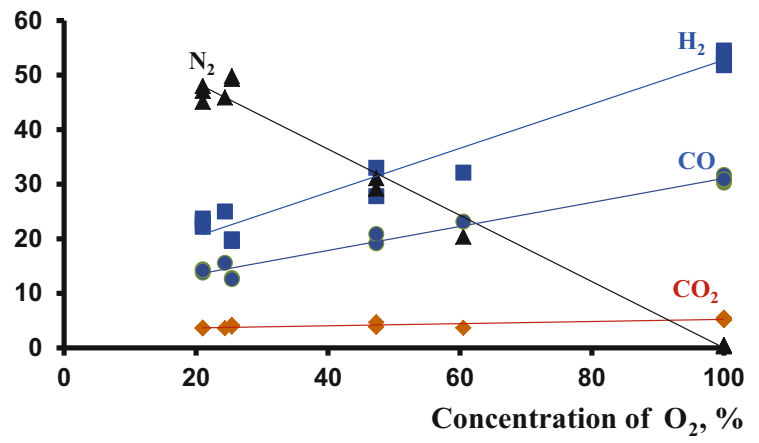

\section{Concentration, $\%$}
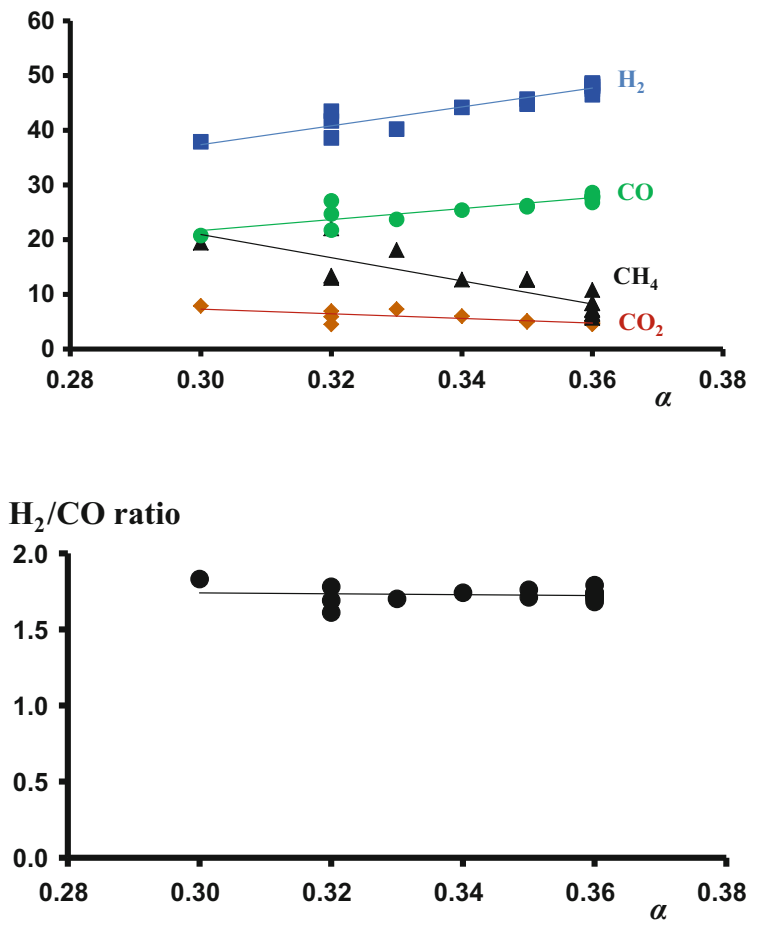

Fig. 6 Dependence of the $\mathrm{H}_{2} / \mathrm{CO}$ ratio at methane conversion by oxygen on oxygen excess coefficient $\alpha$ under consideration to reach the same figures as at the oxidation by air. The main purpose of incomplete methane conversion by oxygen is the overheating of matrixes.

Very important figure for stable operation of converter is the optimal choice of the oxygen excess coefficient $\alpha$. Figure 5 represents the dependence of the concentration of principal syngas components on oxygen excess coefficient at methane 
Fig. 7 Dependence of the concentrations of principal syngas components on the time of pilot testing at methane conversion by oxygen. Oxygen excess coefficient $\alpha=0.36$

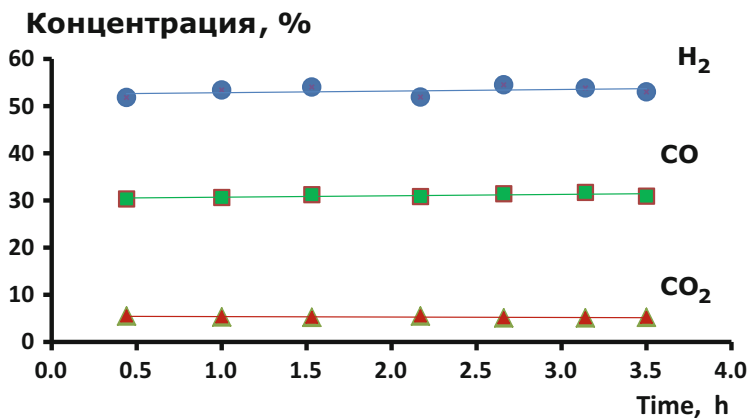

conversion by oxygen. As it can be seen, the optimal value of this ratio is about 0.36. The further increase of this value although increases the conversion of methane can involve the overheating of matrix and thus instability in its operation.

One of the important parameters that characterize the attractiveness of any technology of syngas production is $\mathrm{H}_{2} / \mathrm{CO}$ ratio. As it was experimentally revealed, at matrix conversion of methane by oxygen this parameter is practically independent on the value of oxygen excess coefficient (Fig. 6). At optimal values of oxygen excess coefficient $\alpha=0.34-0.36$ this ratio slightly increases with increasing of oxygen content in oxidizer (Table 1).

Stability of obtained parameters of matrix conversion of natural gas into syngas was tested in several series of time testing. Each series lasted during several hours of continuous operation at stable process conditions. As it can be seen in Fig. 7, all parameters were stable enough during testing period.

Therefore, the possibility of stable long-run matrix conversion of natural gas (methane) by oxygen with obtaining nitrogen-free syngas with parameters well suit for its further use in processes of methanol or Fischer-Tropsch synthesis, as well as for many other practical applications, was demonstrated.

\section{Conclusions}

This study has demonstrated the possibility and good practical prospects of principally new type of non-catalytic matrix reformers for natural gas conversion into syngas. Matrix reformers can operate with all types of oxidizers using air, enriched air, and oxygen, thus producing syngas with given nitrogen content depending on demand, including nitrogen-free syngas for petrochemical applications. The optimal values of oxygen excess coefficient $\alpha=0.34-0.36$ lead to the gain high conversion of reagents and obtain in such simple non-catalytic process very high yield of nitrogen-free syngas with a concentration of $\mathrm{H}_{2}$ more than $50 \%$, that of $\mathrm{CO}$ more than $30 \%$, and $\mathrm{H}_{2} / \mathrm{CO}$ ratio about 1.7 . 
Acknowledgments Research is conducted with the financial support of the state represented by the Ministry of Education and Science of the Russian Federation. Agreement (contract) no. 14.607.21.0037, June 5, 2014 Unique project Identifier: RFMEF160714X0037.

\section{References}

1. Kvenvolden, K.A.: Chem. Geol. 71, 41 (1988)

2. Hobbs, H.O. Jr., Adair, L.S.: Analysis shows GTL viable alternative for US gas producers. Oil Gas J. 68-75 (2012). Accessed 6 Aug 2012

3. Arutyunov, V.S.: Oxidative conversion of natural gas. KRASAND (URSS), 640 p. Moscow, (2011) (in Russian)

4. Arutyunov, V.S., Shmelev, V.M., Lobanov, I.N., Politenkova, G.G.: A generator of synthesis gas and hydrogen based on a radiation burner. Theoretical. Found. Chem. Eng. 44(1), 20-29 (2010)

5. Arutyunov, V.S., Shmelev, V.M., Sinev, M.Yu., Shapovalova, O.V.: Syngas and hydrogen production in a volumetric radiation burners. Chem. Eng. J. 176-177, 291-294 (2011)

6. Shapovalova, O.V., Young Nam Chun, Arutyunov, V.S., Shmelev, V.M.: Syngas and hydrogen production from biogas in 3D matrix reformers. Int. J. Hydr. Eng. 37(19), 14040 14046 (2012)

7. Arutyunov, V.S., Shmelev, V.M., Rakhmetov, A.N., Shapovalova, O.V., SÄtrekova, L.N., Zakharov, A.A. Oxidative conversion of hydrocarbon gases in the surface combustion mode. Russ. Chem. Bull. (International Edition). 62(7), 1504-1509 (2013)

8. Arutyunov, V.S., Shmelev, V.M., Rakhmetov, A.N., Shapovalova, O.V.: 3D matrix burners: a method for small-scale syngas production. Ind. Eng. Chem. Res. 53(5), 1754-1759 (2014)

9. Bouma, P.H., Goey, L.P.H.: Premixed combustion on ceramic foam burners. Comb. Fl. 119, 133 (1999)

10. Nemoda, S., Trimis, D., Zivkovic, G.: Numerical simulation of porous burners and hole plate surface burners. Therm. Sci. 8, 3 (2004)

11. Shmelev, V.M.: Combustion of natural gas at the surface of a high-porosity metal matrix. Russ. J. Phys. Chem. B. 4, 593 (2010)

12. Shmelev, V.M., Nikolaev, V.M., Arutyunov, V.S.: Energy-efficient combustors based on volumetric matrixes. Gazokhimiya 4(8), 28 (2009) (in Russian)

13. Arutyunov, V.S., Shmelev, V.M., Rakhmetov, A.N., Shapovalova, O.V., Zakharov, A.A., Roschin, A.V.: New approaches to development of low-emission combustion chambers for gas turbine engines. Int. Sci. J. Altern. Energy Ecol. (ISJAEE). 6(128), 105-120 (2013)

14. Rakhmetov, A.N., Shmelev, V.M, Arutyunov, V.S.: Low emission combustion chambers for gas turbine engines based on permeable volumetric matrixes. Combust. Plasmachemistry 2 , 83-91 (2013)

15. Jess, A., Popp, R., Hedden, K.: Fischer-Tropsch-synthesis with nitrogen-rich syngas. Fundamentals and reactor design aspects. Appl. Catal. A. 186, 321-342 (1999)

16. Arutyunov, V.S., Savchenko, V.I., Sedov, I.V.: On the prospects of field gas-chemical technologies based on nitrogen containing syngas. Neftegazokhimia. № 4, 12-21 (2016) (in Russian) 
Open Access This chapter is licensed under the terms of the Creative Commons Attribution 4.0 International License (http://creativecommons.org/licenses/by/4.0/), which permits use, sharing, adaptation, distribution and reproduction in any medium or format, as long as you give appropriate credit to the original author(s) and the source, provide a link to the Creative Commons license and indicate if changes were made.

The images or other third party material in this chapter are included in the chapter's Creative Commons license, unless indicated otherwise in a credit line to the material. If material is not included in the chapter's Creative Commons license and your intended use is not permitted by statutory regulation or exceeds the permitted use, you will need to obtain permission directly from the copyright holder.

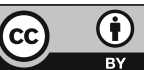

